\title{
NEW PIG DISEASE IN HUNGARY: POSTWEANING MULTI- SYSTEMIC WASTING SYNDROME CAUSED BY CIRCOVIRUS (SHORT COMMUNICATION)
}

\author{
I. KISS ${ }^{1}$, S. KeCSKEMÉTI ${ }^{1}$, T. TUBOLY ${ }^{2 *}$, E. BAJMÓCY ${ }^{1}$ and J. TANYI ${ }^{1}$ \\ ${ }^{1}$ Veterinary Institute of Debrecen, H-4002 Debrecen, P.O. Box 51, Hungary; ${ }^{2}$ Veterinary \\ Medical Research Institute, Hungarian Academy of Sciences, Budapest, Hungary
}

(Received February 21, 2000; accepted May 3, 2000)

\begin{abstract}
Postweaning multisystemic wasting syndrome (PMWS), a new disease in Hungary, was recognized in a swine herd located in Southeast Hungary, during the early winter of 1999. The first clinical signs of paleness, anaemia, and leanness appeared immediately after weaning, at the age of 40-50 days. Pustules were frequently observed on the skin of the trunk, and signs of necrotic dermatitis were also visible. A syndrome of poor growth and wasting was characteristic of the affected pigs. A porcine circovirus (PCV), the suspected causative agent, was detected by polymerase chain reaction (PCR). Sequencing data and restriction endonuclease (RE) analysis of the PCR products suggested that the virus belonged to the PCV-II group where all the causative agents of PMWS are also grouped.
\end{abstract}

Key words: Porcine circovirus (PCV), postweaning multisystemic wasting syndrome (PMWS)

Porcine circovirus (PCV) was initially recognized in Germany (Tischer et al., 1974; Tischer et al., 1982) as a contaminant of continuous pig kidney cell lines. It had been considered an apathogenic virus until recently when a connection between PCV and the postweaning multisystemic wasting syndrome (PMWS) of pigs was established in Canada (Ellis et al., 1998).

Porcine circoviruses can be divided into two groups based on their antigenic properties and nucleotide composition: PCV-I comprises apathogenic viruses that contaminate pig cell lines while the members of PCV-II are the recognized causative agents of PMWS (Allan et al., 1998). Based on serological studies PCV-I occurs in Germany (even in wild boars) (Tischer et al., 1986; Tischer et al., 1995), Northern Ireland (Allan et al., 1994), Canada (Dulac and Afshar, 1989), Great Britain (Edwards and Sands, 1994), and New Zealand (Horner, 1991). PMWS caused by PCV-II has been reported from Ireland (Spillane et al., 1998), Northern Ireland (Kennedy et al., 1998; Meehan et al., 1998), France (LeCann et al., 1997), Spain (Segalés et al., 1997), Canada (Clark, 1997), the USA (Daft et al., 1996), Denmark (Allan et al., 1999), South Korea (Choi and

*Corresponding author. E-mail: tuboly@novell.vmri.hu; Fax: +36 (1) 467-4076 
Chae, 1999), and Japan (Onuki et al., 1999). This is the first report based on clinical and pathological findings, confirmed by polymerase chain reaction (PCR) assay, of the presence of PCV-II and PMWS in Hungary.

\section{Case history}

A syndrome of poor growth and wasting in weaned pigs was reported to the Veterinary Institute of Debrecen, Hungary during the early winter of 1999. The affected stock, located in Southeast Hungary, had been established four years ago. The stock of 700 sows had achieved a good level of productivity and it had been free of significant pig pathogens.

\section{Clinical observations}

The onset of the clinical signs was usually observed at the age of 40-50 days (shortly after weaning) though earlier occurrence was noticed in few cases. The affected animals showed retarded growth, failure to gain weight and became dull (Fig. 1). Clinical investigations revealed paleness, anaemia, sometimes severe emaciation, rough and long hair, tachypnoea or dyspnoea and coughing in a few cases. Some animals showed jaundice and/or pneumonia and diarrhoea. The frequent occurrence of pustules over the skin of the trunk and signs of necrotic dermatitis at the tip of the tail and at the edges of the ears indicated severe impairment of the pigs' general condition. A small proportion of the affected animals died within a few days after the onset of the first clinical signs and the majority of the diseased pigs died within two to three weeks. The separation of the clinically sick animals almost absolutely prevented the spread of the disease. Morbidity and mortality reached $30 \%$ and $15 \%$, respectively. The reproductive status and management of the stock were satisfactory and the fattening line was not affected by any severe malcondition.

\section{Pathological findings}

The most significant pathological findings observed in 29 pigs subjected to postmortem examination were the following: the lymph nodes were pale and enlarged throughout the body, but the mesenteric ones showed the most severe changes. The pleural cavities contained a large amount of yellow, viscous pleural fluid, the lungs were oedematous, and hydropericardium was observed in several cases (Figs 2 and 3). In addition to the above findings, signs similar to mulberry heart disease but without the haemorrhages of the heart, subacute interstitial bronchopneumonia, and dystrophy of the liver were also noticed in some cases. 


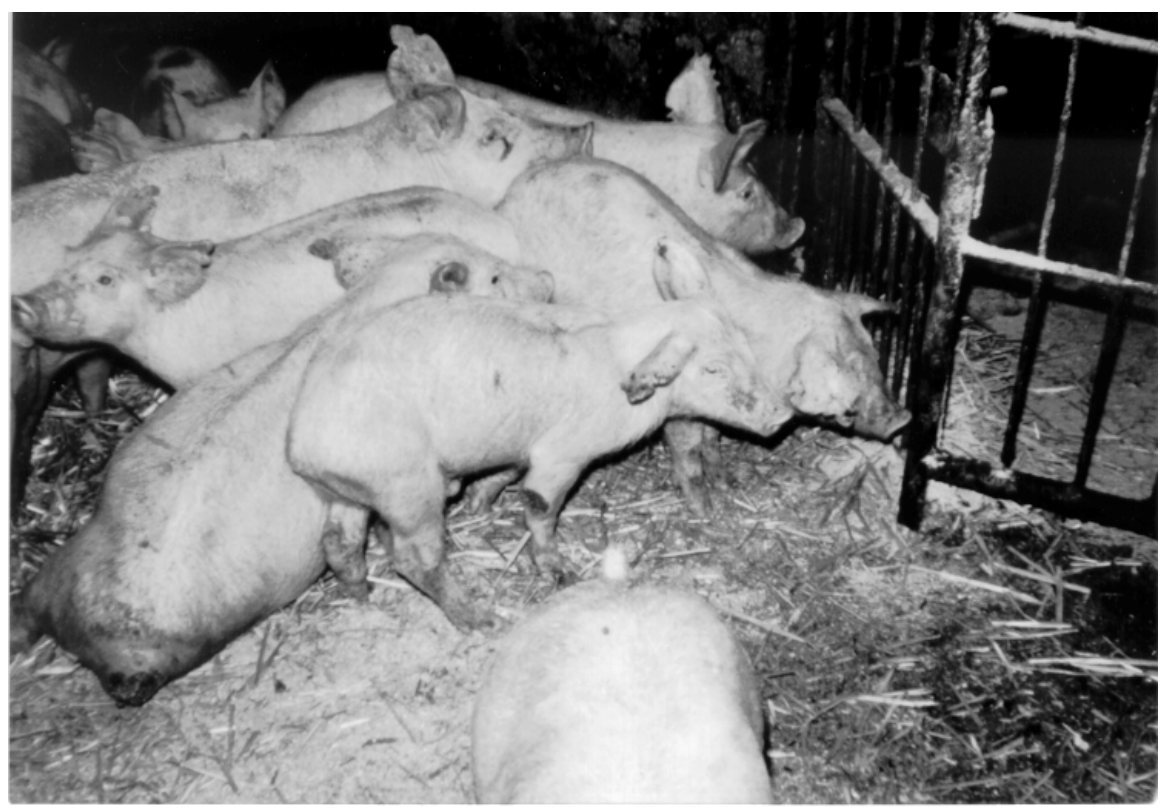

Fig. 1. Clinical picture of circovirus-affected pigs. Some of the animals seem dull, retarded in growth, and hairy

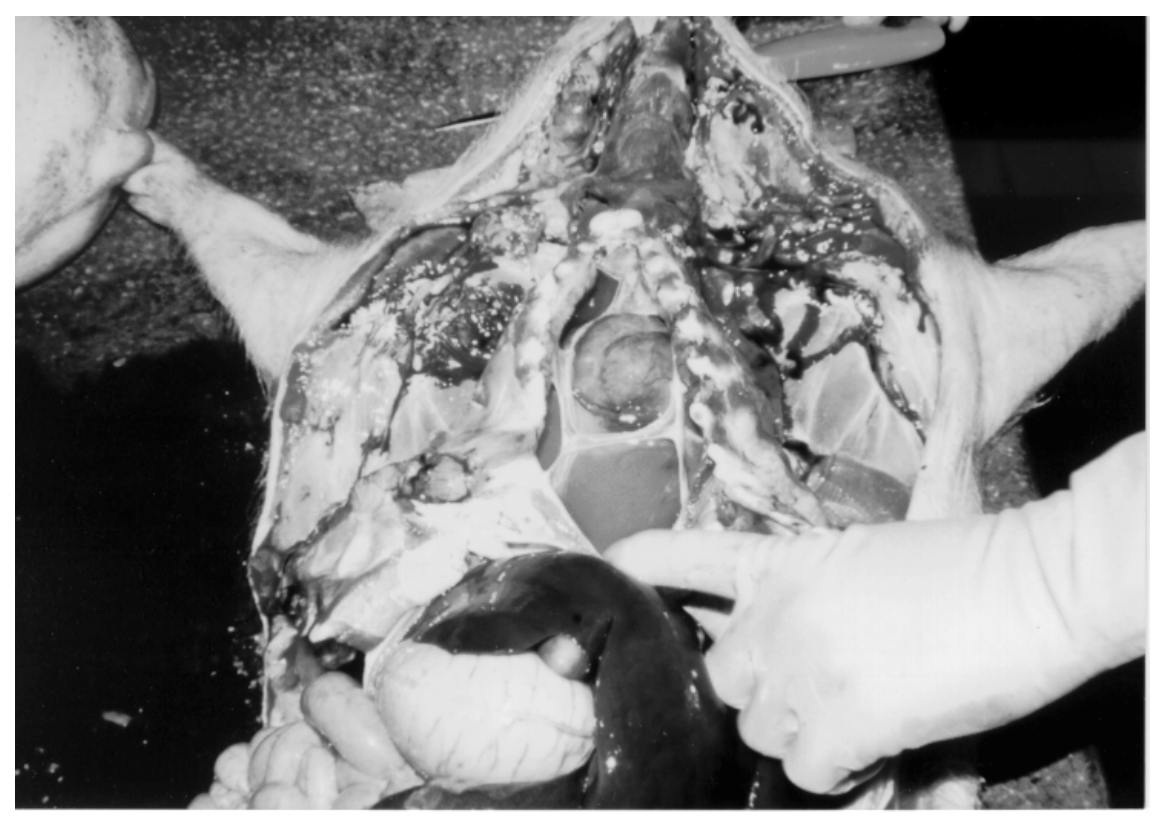

Fig. 2. Necropsy of the dead animals revealed accumulation of a large amount of viscous pleural fluid, and severe hydropericardium 


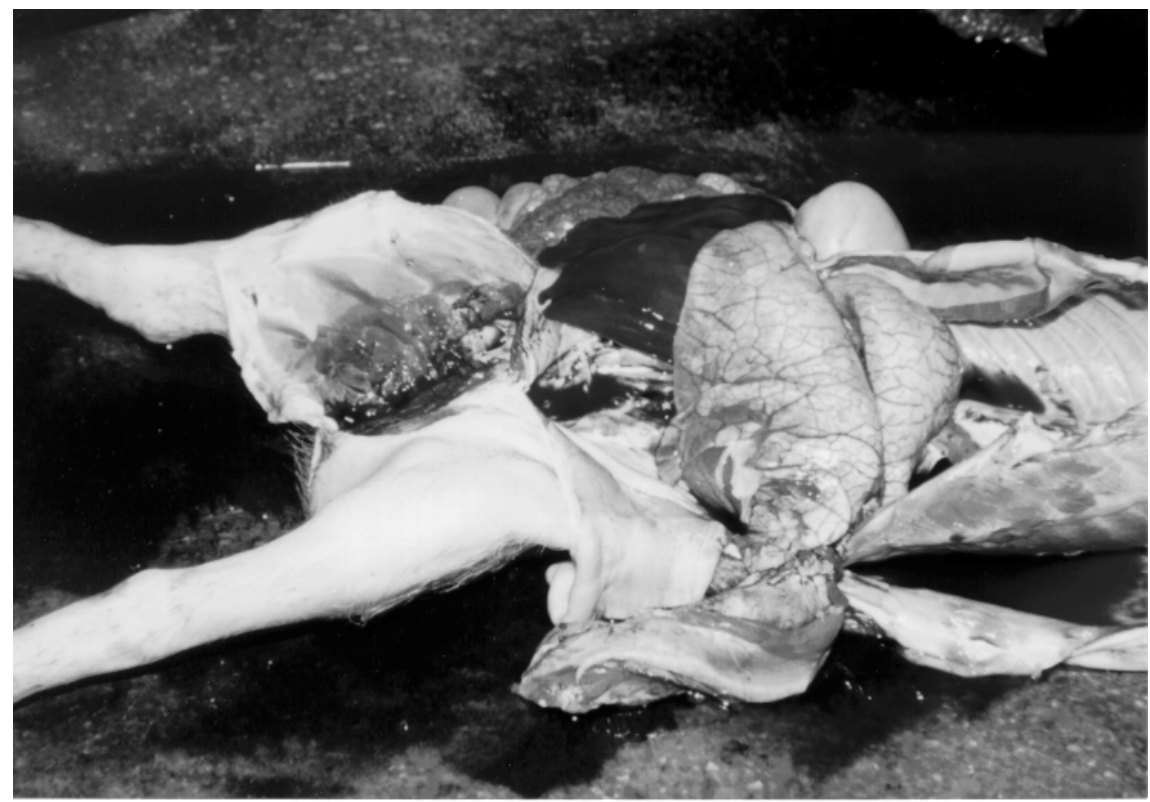

Fig. 3. Characteristic pathological finding of PMWS: lung oedema

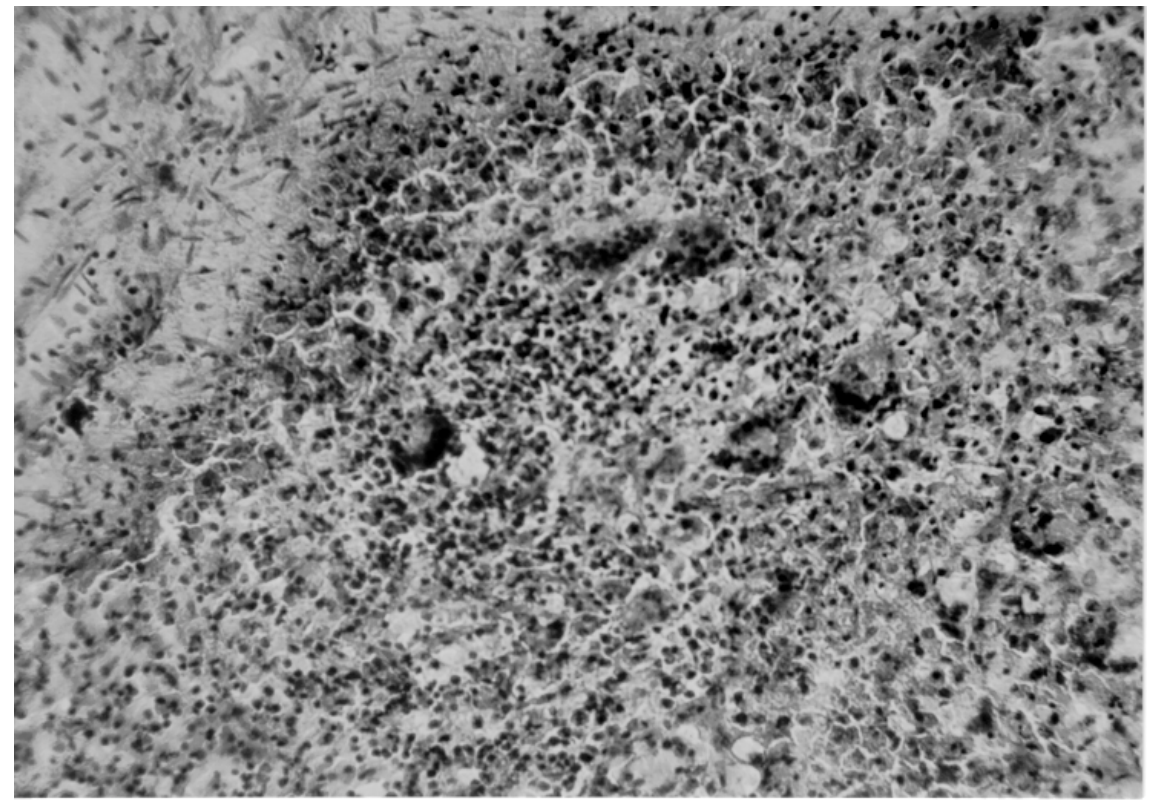

Fig. 4. Histopathological findings in the lymph nodes. The affected tissues showed macrophage infiltration, formation of syncytia formation, lymphoid cell depletion, and giant cell formation. Haematoxylin and eosin, $\times 160$ 
The histopathological examinations revealed severe macrophage infiltration, syncytia formation, lymphoid cell depletion and giant cell formation in the lymphoid tissues (Fig. 4). In addition to the histological evidence of oedema in the lungs, perivascular hyperplasia of histiocytes and lymphoid cells was observed.

Pasteurella multocida was isolated in some cases from the lungs; otherwise the organs were bacteriologically negative. Efforts to demonstrate the presence of eperythrozoons as causative agents for the necrotic changes gave no positive result. Similarly, no fumonisin B1 toxin could be demonstrated in the feed, as one could expect it to explain the sometimes enormous extent of oedema in the lungs.

\section{Polymerase chain reaction}

In order to demonstrate the presence of PCV in the different organs of the 29 autopsied pigs, polymerase chain reactions (PCR) were carried out. Primers were designed based on the available Genbank circovirus sequence data, targeting sequences that are fully conserved among all known PCV isolates to ensure the detection of possible genomic variants. The calculated size of the PCR product, using these primers (Circ1: 5'- AGGCGACCGCAGAAGAAG -3', and Circ2: 5'-TGGTACTCCTCAACTGCTGTCC -3') was 886 base pairs. The primers flanked a sequence that is variable between PCV-I and PCV-II viruses, providing a simple way of differentiating the two groups by restriction endonuclease (RE) analysis. Lungs, bone marrow, spleen, liver, kidney, mesenteric and mediastinal lymph nodes served as targets and the nucleic acid content of the samples was extracted as described earlier (Kiss et al., 1996). The PCR was carried out under the conditions according to Kiss et al. (1996). Figure 5 shows the undigested DNA amplified from a lung sample, together with PCV positive and negative controls (kindly provided by Dr. Yuehua Cai, Animal Health Laboratories, Guelph, Canada). The resulting products migrated at the expected size during agarose gel electrophoresis. The DNA products were digested with $\mathrm{XbaI}$ and EcoRI REs, which are able to distinguish PCV-I and PCV-II. XbaI digested PCR products (PCV-II) of the lung samples from four different pigs and from the bone marrow, spleen and mediastinal lymph node of the same pig are also shown in Fig. 5. All 29 pigs were positive in PCR, the lungs reacted in 20 cases, the mediastinal lymph nodes in 17 cases, the bone marrow in 28 cases and the spleen in 22 cases. A number of PCR products were purified from the gel and sequenced in both directions with the two PCR primers, using an ABI PRISM sequencing device. The sequences of the PCR products were compared to the data deposited in the Genbank and it was verified that they originated from a type II porcine circovirus (data not shown). 


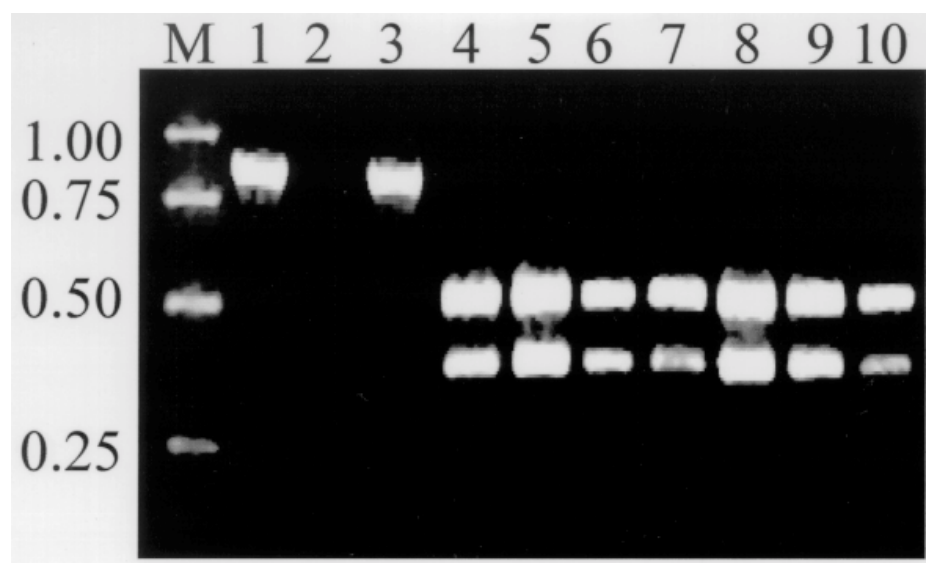

Fig. 5. Agarose gel electrophoresis of PCR products. Lane M: molecular weight marker (sizes in kilobase pairs are indicated on the left); lane 1: lung sample; lane 2: negative control; lane 3: positive control; lanes 4-7: $X b a$ I digested PCR products from the lungs of different pigs; lanes 8-10: $X b a \mathrm{I}$ digested amplicons of 8: bone marrow, 9: spleen, 10: mediastinal lymph node of the same pig (of lane 7)

\section{Conclusion}

Based on the above clinical, gross and histopathological findings, and on the performed molecular biological investigations it was concluded that the observed disease was PMWS. So far this is the first report on the appearance of PCV and consequently PMWS in Hungary. Although all other causative agents could be excluded, further studies are needed to fulfil the third element of Koch's postulates with circoviruses isolated from infected pigs. As a result of the findings described in this paper, a wider epidemiological survey has been started in our institute to size the PCV-affected areas of the country and to determine the possible origin of this newly diagnosed virus.

\section{References}

Allan, G. M., McNeilly, F., Meehan, B. M., Kennedy, S., Mackie, D. P., Ellis, J. A., Clark, E. G., Espuna, E., Saubi, N., Riera, P., Botner, A. and Charreyre, C. E. (1999): Isolation and characterisation of circoviruses from pigs with wasting syndromes in Spain, Denmark and Northern Ireland. Vet. Microbiol. 66, 115-123.

Allan, G. M., Meehan, B., Todd, D., Kennedy, S., McNeilly, F., Ellis, J., Clark, E. G., Harding, J., Espuna, E., Botner, A. and Charreyre, C. (1998) Novel porcine circoviruses from pigs with wasting disease syndromes. Vet. Rec. 142, 467-468.

Allan, G. M., Phenix, K. V., Todd, D. and McNulty, M. S. (1994): Some biological and physicochemical properties of porcine circovirus. J. Vet. Med. Ser. B 41, 17-27. 
Choi, C. and Chae, C. (1999): In-situ hybridization for the detection of porcine circovirus in pigs with postweaning multisystemic wasting syndrome. J. Comp. Pathol. 3, 265-270.

Clark, E. G. (1997): Post-weaning multisystemic wasting syndrome. Proc. Am. Ass. Swine. Pract. 10, 499-501.

Daft, B., Nordhausen, R. W., Latimer, K. S. and Niagro, F. D. (1996): Interstitial pneumonia and lymphadenopathy associated with circoviral infection in a 6-week-old pig. Proc. Am. Ass. Vet. Lab. Diagn. 39, 32.

Dulac, G. C. and Afshar, A. (1989): Porcine circovirus antigens in PK-15 cell line (ATCC CCL-33) and evidence of antibodies to circovirus in Canadian pigs. Can. J. Vet. Res. 53, 431-433.

Edwards, S. and Sands, S. S. (1994): Evidence of circovirus infection in British pigs. Vet. Rec. 134, 680-681.

Ellis, J., Hassard, L., Clark, E., Harding, J., Allan, G., Willson, P., Strokappe, J., Martin, K., McNeilly, F., Meehan, B., Todd, D. and Haines, D. (1998): Isolation of circovirus from lesions of pigs with multisystemic wasting syndrome. Can. Vet. J. 39, 44-51.

Horner, G. W. (1991): Pig circovirus antibodies present in New Zealand pigs. SurveillanceWellington 18, 23.

Kennedy, S., Allan, G., McNeilly, F., Adair, B. M., Hughes, A. and Spillane, P. (1998): Porcine circovirus infection in Northern Ireland. Vet. Rec. 142, 495-496.

Kiss, I., Matiz, K., Bajmócy, E., Rusvai, M. and Harrach, B. (1996): Infectious canine hepatitis: detection of canine adenovirus type 1 by polymerase chain reaction. Acta Vet. Hung. 44, 253-258.

LeCann, P., Albina, E. and Medac, F. (1997): Piglet wasting disease. Vet. Rec. 141, 660.

Meehan, B. M., McNeilly, F., Todd, D., Kennedy, S., Jewhurst, V. A., Ellis, J. A., Hassard, L. E., Clark, E. G., Haines, D. M. and Allan, G. M. (1998): Characterization of novel circovirus DNAs associated with wasting syndromes in pigs. J. Gen. Virol. 79, 2171-2179.

Onuki, A., Abe, K., Togashi, K., Kawashima, K., Taneichi, A. and Tsunemitsu, H. (1999): Detection of porcine circovirus from lesions of a pig with wasting disease in Japan. J. Vet. Med. Sci. 10, 1119-1123.

Segalés, J., Sitjar, M., Domingo, M., Dee, S., Del Pozo, M., Noval, R., Sacristan, C., De las Heras, M., Ferro, A. and Latimer, S. (1997): First report of postweaning multisystemic wasting syndrome in pigs in Spain. Vet. Rec. 141, 600-601.

Spillane, P., Kennedy, S., Meehan, B. and Allan, G. (1998): Porcine circovirus infection in the Republic of Ireland. Vet. Rec. 142, 511-512.

Tischer, I., Bode, L., Peters, D., Pociali, S. and Germann, B. (1995): Distribution of antibodies to porcine circovirus in swine populations of different breeding farms. Arch. Virol. 140, 737-743.

Tischer, I., Gelderblom, H., Vetterman, W. and Koch, M. A. (1982): A very small porcine virus with a circular stranded DNA. Nature 295, 64-66.

Tischer, I., Mields, W., Wolff, D., Vagt, M. and Griem, W. (1986): Studies on the pathogenicity of porcine circovirus. Arch. Virol. 91, 271-276.

Tischer, I., Rasch, R. and Tochtermann, G. (1974): Characterization of papovavirus- and picornavirus-like particles in permanent pig kidney cell lines. Zbl. Bakteriol. A, 226, 153-167. 